\title{
A randomized study of a smartphone application compared with booklet to improve service user's knowledge of their legal rights
}

\author{
B. $\mathrm{O}^{\prime}$ Donoghue ${ }^{1,2,3 *}$ E. Roche ${ }^{4}$, A. Naji ${ }^{5}$, R. Daly ${ }^{6}$, K. Madigan $^{7}$, I. Cole ${ }^{8+}$ and J. Lyne ${ }^{6+}$ \\ ${ }^{1}$ Orygen, the National Centre of Excellence in Youth Mental Health, Melbourne, VIC, Australia \\ ${ }^{2}$ Centre for Youth Mental Health, University of Melbourne, Melbourne, VIC, Australia \\ ${ }^{3}$ Orygen Youth Health, Melbourne, VIC, Australia \\ ${ }^{4}$ North Dublin Mental Health Services, Curam Clinic, Swords, Co. Dublin, Ireland \\ ${ }^{5}$ Royal College of Surgeons in Ireland, St. Stephen's Green, Dublin, Ireland \\ ${ }^{6}$ North Dublin Mental Health Services, Royal College of Surgeons in Ireland, St. Stephen's Green, Dublin, Ireland \\ ${ }^{7}$ St John of God Community Mental Health Services, Stillorgan, Co. Dublin, Ireland \\ ${ }^{8}$ Dublin North City Mental Health Services, Dublin, Ireland
}

Background. The Mental Health Act 2001 has introduced significant changes to the process of admission to hospital for individuals affected by mental health disorders. This study aimed to determine whether a newly designed smartphone application could result in an improvement in service users' knowledge of their rights compared with the paper booklet.

\begin{abstract}
Methods. This was a randomized study conducted in an outpatient and day-hospital in North Dublin. Participants were randomized to receive the information booklet as either a smartphone application or in the paper form. A questionnaire which was scored from 0 to 10 was devised and was completed at baseline and at 1-week follow-up.
\end{abstract}

Results. A total of 42 individuals completed the baseline and follow-up questionnaire and of these, 53.7\% were female and the mean age was 38.2 years (S.D. \pm 13.5 ). A total of $34.1 \%$ had a diagnosis of a psychotic disorder, $29.3 \%$ had a depressive disorder and $22 \%$ had bipolar-affective disorder. The mean score before the intervention in the total group was 3.5 (S.D. \pm 2.2 ) and this increased to 5.8 (S.D. \pm 2.2 ) at follow-up. Participants randomized to the smartphone application improving by a mean of 2.5 (s.D. \pm 2.5 ), while those randomized to the booklet improving by a mean of 2.3 (s.D. \pm 2.6 ), which was not statistically significant.

Conclusions. Both forms of the information booklet showed improvement in service users' knowledge of their legal rights. It is possible that each individual will have preference for either a paper form or a smartphone form and this study suggests that both forms should be offered to each individual service user.

Received 7 September 2017; Revised 19 September 2017; Accepted 19 September 2017; First published online 18 October 2017

Key words: Coercion, Mental Health Act 2001, Smartphone Application, randomized trial, hospital admission.

\section{Background}

The last decade has seen substantial changes in the Republic of Ireland to the processes of involuntary admission and legal rights of individuals admitted to hospital for mental health treatment. These changes resulted from the implementation of the Mental Health Act 2001 (MHA2001) (Kelly, 2002) and the establishment of the 'Mental Health Commission,' which aims to promote, encourage and foster high standards and good practices in the delivery of mental health services, and to protect the interests of patients who are involuntarily admitted. These were welcome changes, as prior to the introduction of the MHA2001, it was reported in one

\footnotetext{
* Address for correspondence: B. O'Donoghue, Orygen, the National Centre of Excellence in Youth Mental Health, Melbourne, VIC, Australia.

(Email: briannoelodonoghue@gmail.com)

${ }^{\dagger}$ These authors contributed equally to this work.
}

study that nearly half of individuals were unaware that they had been admitted involuntarily, and only $14 \%$ perceived that they had their rights explained to them on admission (Rooney et al. 1996). Although awareness of legal status was found to have improved substantially following the introduction of the MHA2001 (O'Donoghue et al. 2010), service users continue to have poor knowledge of their rights. For example, it was found that just over half of service users were aware of how mental health tribunals functioned, and over one quarter were unaware that they had the right to appeal the decision of the tribunal (O'Donoghue et al. 2010). A qualitative study of service users' who had been admitted to hospital involuntarily also found that individuals perceived that they had a lack of information and felt disempowered (Murphy et al. 2017).

Ensuring that service users are adequately informed of their rights when admitted to hospital is an 
important duty of the mental health services and this practice could lead to positive change, such as service users feeling more informed, empowered and less apprehensive about an admission to hospital. Providing service users with information on the process of involuntary admission could lead to an improvement in the level of procedural justice perceived and this in turn, could improve the therapeutic relationship and reduce the perception of coercion (Roche et al. 2014). As such, the Mental Health Commission produced an information booklet entitled 'Your guide to the Mental Health Act 2001' which is provided to individuals who are detained involuntarily.

Concurrently over the last decade there has been a dramatic change in how individuals obtain information. A study conducted by the Health Research Board in Ireland that involved over 1500 individuals found that nearly half $(49 \%)$ of people used the internet as a source of information on health (Gallagher et al. 2008). Importantly, the study found that individuals with mental health problems frequently used the internet as a source of information on healthcare.

Therefore, this study aimed to determine whether a smartphone application (app) could result in an improvement in service users' knowledge of their rights under mental health act legislation compared with a paper booklet. It was hypothesized that individuals who received the information via smartphone app would have a greater improvement in knowledge compared with those allocated to the paper booklet.

\section{Methodology}

\section{Setting and participants}

This study took place in the Swords outpatient mental health clinic and day-hospital in North Dublin Mental Health Services. Individuals attending these services were informed of the study and invited to participate. Exclusion criteria included an inability to provide informed consent or an inability to read English. Service users attending outpatient clinics and day hospitals were invited to participate as these were individuals who could potentially be admitted to hospital.

\section{Intervention}

There were two allocation groups in this study. One group received the booklet 'Your Guide to the Mental Health Act 2001' via a smartphone app and the other group received it as a paper document. The booklet 'Your Guide to the Mental Health Act 2001' has six sections, entitled: Introduction, Your Rights, Your Admission, Mental Health Tribunals, Mental Health Commission and Support Organisations. The smartphone app replicates the exact wording of the paper booklet. The smartphone app is available for android and iOS (Apple iphone or ipad) systems and for participants who possessed a smartphone or tablet, with their consent, the app was installed on their device. The participants were shown how to use the app and how to navigate the different sections and obtain information, such as using the search function. If a participant did not have a smartphone or if the app was not compatible with their smartphone or tablet, then a tablet computer was made available for them to use at the mental health clinic or day hospital.

\section{Instruments}

A 10 item questionnaire was devised based on information in the booklet 'Your guide to the Mental Health Act 2001' and is attached as an appendix. The questionnaire was reviewed by an external expert in mental health and mental health legislation. The questionnaire was administered before the intervention and after 1 week. The questionnaire was scored from 0 to 10 , with higher scores representing better knowledge of legal rights under the MHA2001. Each item of the questionnaire was allocated a score of one for a correct answer and zero for an incorrect answer.

\section{Study design}

The study design was a two-armed randomized study. It was not possible to maintain blinding for this study, however participants undertook the initial questionnaire prior to randomization and the follow-up questionnaire was self-reporting.

\section{Consent process and randomization}

An information sheet on the study was provided to potential participants and they were informed about the study verbally. If the service user consented to participate in the study, they were asked to first fill out the baseline questionnaire on their knowledge of their legal rights. Following this, participants were randomized by generating a random number between 1 and 2, with each number representing the allocation to a specific arm of the study, using the website www. random.org. This method facilitated immediate allocation and the appropriate intervention was then delivered.

\section{Power analysis}

The questionnaire is scored from 0 to 10 , with the higher scores representing higher knowledge. It was estimated that a clinically significant difference in knowledge would be represented by a difference of 2 , therefore with $90 \%$ power at a significance level of 0.05 , it was 
estimated that a total of 40 participants would be required (20 in each arm).

\section{Statistical analysis}

Descriptive statistics including means and standard deviations for parametric data were used. For the primary outcome, a $t$-test was conducted to determine whether the mean differences in baseline and follow-up scores differed between the intervention groups. Paired $t$-tests were used to determine whether baseline and follow-up data differed. $\chi^{2}$ Tests were performed to determine if there were differences between categorical groups. Statistical analysis was conducted using IBM SPSS version 24 (IBM, 2011).

\section{Ethical approval and copyright permission}

Ethical approval was obtained from the Beaumont Hospital Ethics Committee. The Mental Health Commission provided permission for the booklet 'Your Guide to the Mental Health Act 2001' to be converted into a smartphone app.

\section{Results}

\section{Description of participants}

A total of 52 individuals were screened for eligibility and of these, one individual was not eligible. Of the 51 individuals eligible, $94.1 \%(n=48)$ provided consent to participate and completed the baseline assessment and of these, $87.5 \%(n=42)$ completed the follow-up questionnaire. The flow diagram of recruitment of participants is displayed in Fig. 1. One individual provided consent to participate in the study but not for their clinical file to be accessed and therefore demographic and clinical information is missing for this participant. A total of $53.7 \%(n=22)$ of participants were females and the mean age of the total cohort was 38.2 years (S.D. \pm 13.5$)$. A total of $34.1 \%(n=14)$ had a diagnosis of a psychotic disorder, $29.3 \%(n=12)$ had a depressive disorder and $22 \%(n=9)$ had a diagnosis of bipolaraffective disorder. The demographic and clinical characteristics of participants is presented in Table 1 and there were no differences between the group allocated to the smartphone app compared to the paper booklet.

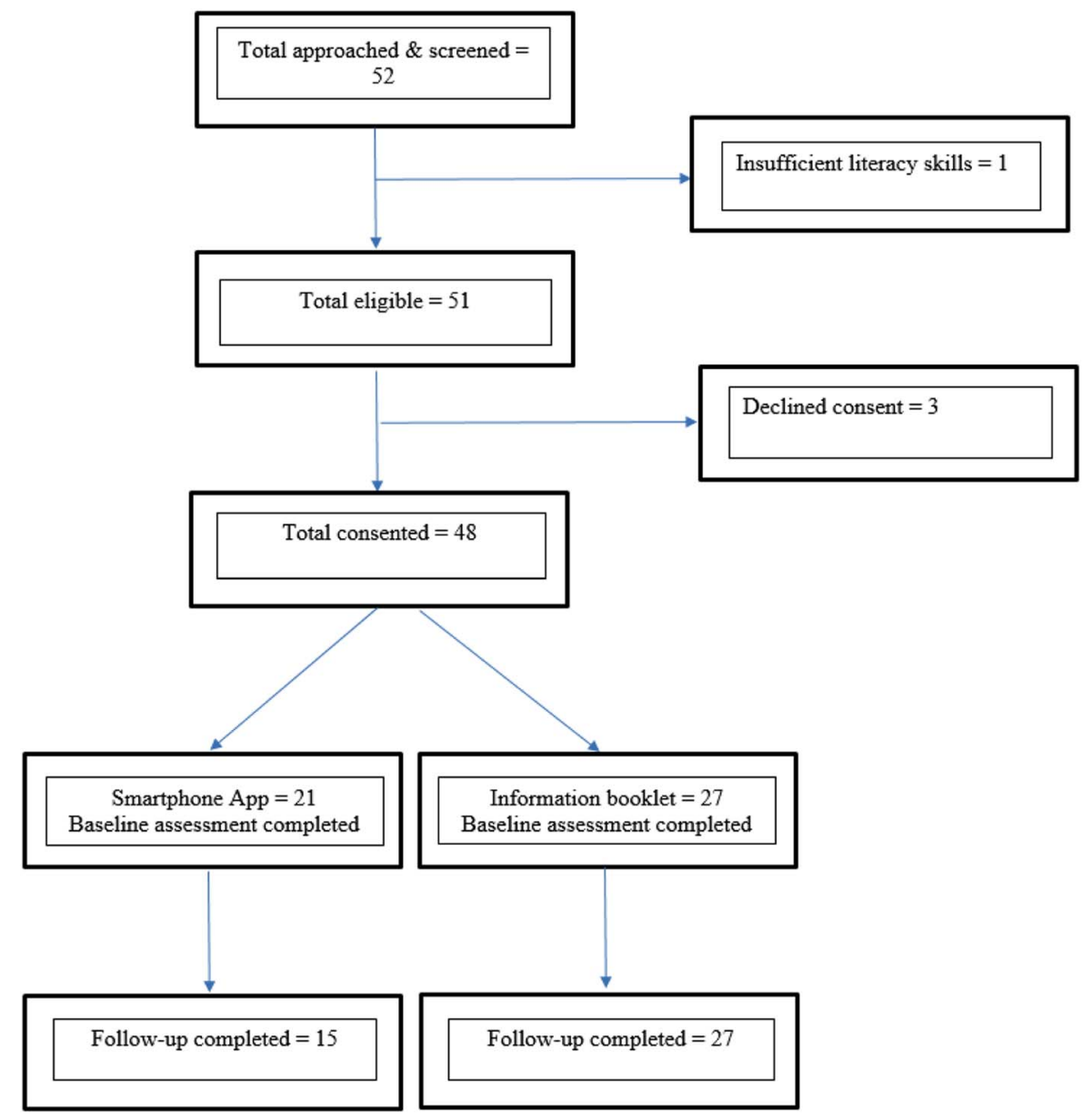

Fig. 1. Flow diagram of recruitment of participants. 
Table 1. Demographic and clinical characteristics of participants and comparison according to group allocation

\begin{tabular}{|c|c|c|c|c|c|c|c|c|}
\hline & \multicolumn{2}{|c|}{ Total cohort } & \multicolumn{2}{|c|}{ Smartphone app } & \multicolumn{2}{|c|}{ Paper booklet } & \multicolumn{2}{|c|}{ Statistical test } \\
\hline & $n$ & $\%$ & $n$ & $\%$ & $n$ & $\%$ & $\chi^{2}$ & $p$ \\
\hline \multicolumn{9}{|l|}{ Sex } \\
\hline Male & 19 & 46.3 & 7 & 50.0 & 12 & 44.4 & 0.11 & 0.74 \\
\hline \multirow[t]{2}{*}{ Female } & 22 & 53.7 & 7 & 50.0 & 15 & 55.6 & & \\
\hline & Mean & S.D. & Mean & S.D. & Mean & S.D. & $t$-Test & $p$ \\
\hline \multirow[t]{2}{*}{ Mean age } & 38.2 & 13.5 & 41.9 & 12.6 & 36.4 & 13.8 & 1.24 & 0.22 \\
\hline & $n$ & $\%$ & $n$ & $\%$ & $n$ & $\%$ & $\chi^{2}$ & $p$ \\
\hline \multicolumn{9}{|l|}{ Marital status } \\
\hline Single & 22 & 53.7 & 6 & 50.0 & 16 & 64.0 & 1.11 & 0.57 \\
\hline Married/defacto & 9 & 22.0 & 3 & 25.0 & 6 & 24.0 & & \\
\hline Separated/divorced & 6 & 14.6 & 3 & 25.0 & 3 & 12.0 & & \\
\hline Not documented & 4 & 9.7 & 0 & & & & & \\
\hline \multicolumn{9}{|l|}{ Employment } \\
\hline Competitive employment & 12 & 29.3 & 4 & 26.7 & 8 & 29.6 & 6.11 & 0.30 \\
\hline Unemployed & 17 & 41.4 & 7 & & 10 & & & \\
\hline Not recorded & 12 & 29.3 & 3 & & 9 & & & \\
\hline \multicolumn{9}{|l|}{ Diagnosis } \\
\hline Psychotic disorder & 14 & 34.1 & 7 & 50.0 & 7 & 25.9 & 6.41 & 0.38 \\
\hline Depressive disorder & 12 & 29.3 & 4 & 28.6 & 8 & 29.6 & & \\
\hline Bipolar-affective disorder & 9 & 22.0 & 1 & 7.1 & 8 & 29.6 & & \\
\hline Anxiety disorder & 2 & 4.9 & 1 & 7.1 & 1 & 3.7 & & \\
\hline Personality disorder & 4 & 9.8 & 1 & 7.1 & 3 & 11.1 & & \\
\hline \multicolumn{9}{|l|}{ Previous admissions } \\
\hline Previous voluntary admissions & 16 & 44.4 & 7 & 53.8 & 9 & 39.1 & 0.73 & 0.39 \\
\hline Previous involuntary admissions & 4 & 11.8 & 2 & 15.4 & 2 & 9.5 & 0.27 & 0.63 \\
\hline No previous admissions & 20 & 47.6 & 6 & 40.0 & 14 & 51.9 & 0.54 & 0.46 \\
\hline
\end{tabular}

\section{Knowledge of legal rights}

The mean score of the questionnaire prior to the intervention in the total group was 3.5 (S.D. \pm 2.2 ) out of a potential score of 10 and there was no difference in the baseline scores between groups (3.1 v. 3.6, $t=-0.86, \mathrm{df}=40, p=0.39$ ). In the total cohort, the mean score of the questionnaire following the intervention was 5.8 (S.D. \pm 2.2 ). There was no difference in the scores between groups following the intervention (5.5 v. 6.0, $t=-0.61, \mathrm{df}=40, p=0.55)$. There was a mean improvement in the scores by 2.4 (s.D. \pm 2.5 ) points in the total cohort and this difference from baseline to follow-up scores was statistically significant $(t=-6.05, \mathrm{df}=41$, $p<0.001)$. Participants randomized to the smartphone application improved by a mean of $2.5(\mathrm{SD} \pm 2.5)$ and those randomized to the booklet improved by a mean of 2.3 (S.D. \pm 2.6$)$, a difference which was not statistically significant $(t=0.21, \mathrm{df}=40, p=0.84)$. The proportion of participant who answered each question correctly before and after the intervention are displayed in Table 2 and this demonstrated that there was an improvement in all questions at follow-up.

\section{Discussion}

\section{Summary of findings}

This study found that service users had an overall poor baseline knowledge of their legal rights under the MHA2001 legislation, however this knowledge improved significantly following allocation to either study interventions, a smartphone application or paper booklet. While there was an improvement in knowledge in the overall group, there was no difference in the level of improvement dependent on allocation to either smartphone application or paper booklet.

\section{Clinical implications}

The results of this study are encouraging, as it has demonstrated that both mediums for providing crucial information to service users regarding their rights are effective and each medium offers its own advantage. If a service user owns a smartphone or tablet, they could be encouraged to download the application on entry to the mental health service and this offers a free, convenient method to readily access ones rights if 
Table 2. Individual item answers pre- and post-intervention

\begin{tabular}{|c|c|c|c|c|c|c|c|c|}
\hline & \multirow[b]{2}{*}{ Question } & \multirow[b]{2}{*}{ Correct answer } & \multicolumn{2}{|c|}{ Total cohort } & \multicolumn{2}{|c|}{$\begin{array}{l}\text { Smartphone app } \\
\text { group }\end{array}$} & \multicolumn{2}{|c|}{ Booklet group } \\
\hline & & & $\begin{array}{l}\text { Correct } \\
\text { pre }(\%)\end{array}$ & $\begin{array}{l}\text { Correct } \\
\text { post }(\%)\end{array}$ & $\begin{array}{l}\text { Correct } \\
\text { pre }(\%)\end{array}$ & $\begin{array}{l}\text { Correct } \\
\text { post }(\%)\end{array}$ & $\begin{array}{l}\text { Correct } \\
\text { pre }(\%)\end{array}$ & $\begin{array}{l}\text { Correct } \\
\text { post }(\%)\end{array}$ \\
\hline 1 & Can a voluntary patient be detained against their will in hospital? & Yes & 40.5 & 59.5 & 36.7 & 53.3 & 48.1 & 63.0 \\
\hline 2 & $\begin{array}{l}\text { After a person makes an application for another person to be admitted to hospital under the } \\
\text { Mental Health Act, how soon must a doctor see them to make a recommendation (or not) } \\
\text { for admission? }\end{array}$ & Within $24 \mathrm{~h}$ & 40.5 & 66.7 & 33.3 & 80.0 & 44.4 & 59.3 \\
\hline 3 & $\begin{array}{l}\text { If a person is brought to hospital under the Mental Health Act, how many consultant } \\
\text { psychiatrists need to assess them within } 24 \mathrm{~h} \text { in order to decide if they need to remain in } \\
\text { hospital involuntarily? }\end{array}$ & 1 & 33.3 & 59.5 & 33.3 & 60.0 & 33.3 & 59.3 \\
\hline 4 & $\begin{array}{l}\text { Can a person be admitted involuntarily if they are addicted to alcohol or drugs and not } \\
\text { suffering with any other mental health disorder? }\end{array}$ & No & 19.0 & 45.2 & 13.3 & 26.7 & 22.2 & 55.6 \\
\hline 5 & How long can an initial involuntary admission order last? & Up to 21 days & 4.8 & 38.1 & 6.7 & 26.7 & 3.7 & 44.4 \\
\hline 6 & Is a person detained under the Mental Health Act entitled to free legal support? & Yes & 73.8 & 78.6 & 73.3 & 66.7 & 74.1 & 85.2 \\
\hline 7 & $\begin{array}{l}\text { The three people who sit on a Mental Health Tribunal must be a lawyer, a consultant } \\
\text { psychiatrist and a mental health nurse? }\end{array}$ & False & 0 & 23.8 & 0 & 20 & 0 & 25.9 \\
\hline 8 & $\begin{array}{l}\text { Do involuntarily admitted service users have the right to appeal the decision of the Mental } \\
\text { Health Tribunal? }\end{array}$ & Yes & 52.4 & 83.3 & 40.0 & 80.0 & 59.3 & 85.2 \\
\hline 9 & $\begin{array}{l}\text { If a service user is discharged or become a voluntary patient before your Mental Health } \\
\text { Tribunal is due, can they have a Tribunal anyway? }\end{array}$ & $\begin{array}{l}\text { Only if formally } \\
\text { requested }\end{array}$ & 23.8 & 47.6 & 20.0 & 53.3 & 25.9 & 44.4 \\
\hline 10 & $\begin{array}{l}\text { Can an involuntarily admitted service user leave the hospital with the approval of your } \\
\text { consultant psychiatrist? }\end{array}$ & Yes & 57.1 & 78.6 & 60.0 & 86.7 & 55.6 & 74.1 \\
\hline
\end{tabular}

${ }^{a}$ This is the original wording of the question, however it should have read: 'After a person makes an application for another person to be admitted to hospital under the Mental Health Act, how soon must a doctor see them to make a recommendation (or not) for admission after receiving the application?* 
admitted. For those service users without a smartphone or tablet, the paper booklet has been demonstrated to be just as effective in improving knowledge on legal rights. Smartphone applications offer other potential benefits for individuals affected by mental health disorders, such as reminders to encourage adherence (Kannisto et al. 2015) and interventions to improve symptoms (Donker et al. 2013) and thus should be seen as an effective and inexpensive method to offer support.

\section{Strengths and limitations}

This study has a number of strengths, in that it was adequately powered to determine if the intervention was effective and it was conducted in a clinical cohort who should be informed of their rights as a service user. However, the findings have to be considered within the limitations of the study. First, it is possible that there could be a test-retest bias by conducting the same questionnaire twice and the initial questionnaire could have focused participants on what information to look for within the smartphone application or paper booklet. Therefore, if used in regular clinical practice, without the initial questionnaire, service users may not obtain as much information from the smartphone application or booklet. The study was also conducted in a clinical cohort who were not inpatients and only a minority of whom had been involuntary inpatients previously. It is not clear whether the interventions would be as effective in an inpatient population, who may be more acutely unwell, which could limit their capacity to retain information (Christensen \& Rogne, 1994). Anecdotally, the practice of restricting service users access to their mobile phones while an inpatient in psychiatric units is known to occur. One of the rationales for this practice is that most mobile phones have camera's built into the phone and this represents a potential threat to other patients confidentiality. However, there appears to be no published literature on this practice or it's justification and the practice varies according to local policies and protocols. If this was the case, it would limit the applicability of the smartphone application in the acute setting, although it could still be given to service users prior to any admission.

\section{Conclusions}

The current study provides initial evidence that a smartphone application may be at least as effective in disseminating information on the MHA2001 to a group of mental health service attenders. Given that some service users may have a preference for this mode of communication, strong consideration should be given to offering this app to service users detained under the MHA2001, in addition to the paper booklet. Future research should focus on developing apps for dissemination of other knowledge within mental health services, and on ensuring service users are appropriately informed when they are treated under Mental Health Act legislation.

\section{Access to smartphone application}

The smartphone application is available on the Android and iOS system. It is available for download free from the Google play store at: https://play.google.com/ store/apps/details?id=com.boostedhuman.mha_guide book_app and also from the iTunes store by searching 'Your guide to the Mental Health Act 2001.'

\section{Acknowledgments}

The authors thank the Mental Health Commission for funding for the production of the smartphone application and also for granting copyright permission to use the content of the booklet: 'Your Guide to the Mental Health Act 2001.' The authors also thank Dr Declan Murray, Consultant Psychiatrist for his support of the project and Dr Larkin Feeney, Consultant Psychiatrist who reviewed the smartphone application during its production. The authors are grateful to Prof Brendan Kelly for reviewing and providing valuable feedback on the questionnaire used in the study. The smartphone application was produced by the company 'Boosted Human,' based in Melbourne, Australia.

\section{Financial Support}

This research received funding from the Mental Health Commission for the production of the smartphone application.

\section{Conflicts of Interest}

All authors declare that they have no conflicts of interest.

\section{Ethical Standards}

The authors assert that all procedures contributing to this work comply with the ethical standards of the relevant national and institutional committee on human experimentation with the Helsinki Declaration of 1975, as revised in 2008. Ethical approval was obtained from the Beaumont Hospital Ethics Committee. The Mental Health Commission provided permission for the booklet 'Your Guide to the Mental Health Act 2001' to be converted into a smartphone app.

\section{References}

Christensen AM, Rogne TA (1994). Involuntary admissions and other compulsions in psychiatry. Patients' knowledge of 
their rights and ability to receive information concerning these matters. Ugeskr Laeger 156, 5300-5303.

Donker T, Petrie K, Proudfoot J, Clarke J, Birch MR, Christensen H (2013). Smartphones for smarter delivery of mental health programs: a systematic review. Journal of Medical Internet Research 15, e247.

Gallagher S, Doherty D, Tedstone Moran R, Katralova-O'Doherty K (2008). Internet use and seeking health information online in Ireland: demographic characteristics and mental health characteristics of users and non users. HRB Research Series 4. (http:/ /www.hrb.ie/ uploads/media/HRBResearchSeries4.pdf).

IBM (2011). IBM SPSS Statistics for Windows, version 21.0. IBM.

Kannisto KA, Adams CE, Koivunen M, Katajisto J, Valimaki M (2015). Feedback on SMS reminders to encourage adherence among patients taking antipsychotic medication: a cross-sectional survey nested within a randomised trial. BMJ Open 5, e008574, doi: 10.1136/ bmjopen-2015-008574.
Kelly BD (2002). The Mental Health Act 2001. Irish Medical Journal 95, 151-152.

Murphy R, McGuinness D, Bainbridge E, Brosnan L, Felzmann H, Keys M, Murphy K, Hallahan B, McDonald C, Higgins A (2017). Service users' experiences of involuntary hospital admission under the Mental Health Act 2001 in the Republic of Ireland. Psychiatric Service. appips201700008. doi: 10.1176/appi.ps.201700008.

O'Donoghue B, Lyne J, Hill M, Larkin C, Feeney L, O'Callaghan E (2010). Involuntary admission from the patients' perspective. Social Psychiatry and Psychiatric Epidemiology 45, 631-638.

Roche E, Madigan K, Lyne JP, Feeney L, O'Donoghue B (2014). The therapeutic relationship after psychiatric admission. Journal of Nervous and Mental Disease 202, 186-192.

Rooney S, Murphy K, Mulvaney F, O'Callaghan E, Larkin C (1996). A comparison of voluntary and involuntary patients admitted to hospital. Irish Journal of Psychological Medicine 13, 132-137. 